\title{
Gris cigale
}

\section{Erhard Taverna}

Dr med., membre de la rédaction

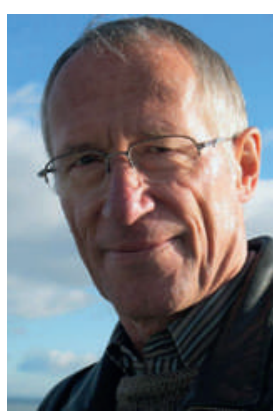

Tithon était un prince mortel qu'Eos, déesse de l'aurore, se choisit pour époux et dont elle eut deux fils. Sur les instances d'Eos, Zeus accorda l'immortalité à Tithon. Mais la déesse avait oublié de demander également la jeunesse éternelle. Le beau prince grisonna, puis blanchit et sa peau se dessécha. Lorsqu'il ne fut plus qu'une enveloppe creusée de rides, Eos l'enferma dans une chambre éloignée, d'après la légende. Dans une autre version, elle le changea en cigale, afin qu'il la réjouisse au moins de son chant et se débarrasse chaque année de son ancienne peau.

Le public sous les voûtes de Calatrava dans le "Pfalzkeller» de Saint-Gall est lui aussi plus ou moins gris cigale. L'auditoire du forum, où il ne reste plus un seul siège libre, écoute attentivement la directrice de la clinique de gériatrie et professeure de Zurich. Elle ne promet pas l'immortalité, mais fait miroiter le modèle de la compression. La phase de morbidité doit, au moins dans la troisième tranche de vie, de 60 à 80 ans, se limiter à une brève période avant la mort naturelle. Une dernière ligne droite sans handicaps, comme tout le monde la rêve. L'atmosphère de renouveau en gérontologie est ponctuée de résultats tirés de la plus grande étude européenne sur la vieillesse. Do-Health a examiné pendant trois ans la prévention des maladies chroniques chez les 70 ans et plus. L'accent était mis sur les fractures, les chutes, l'hypertension, le déclin fonctionnel et cognitif et les douleurs liées à l'arthrose. Do-Health a évalué l'impact de trois stratégies: la vitamine D3, les acides gras oméga-3 et un programme d'exercice physique à domicile. La vitamine $\mathrm{D} 3$ semble être un véritable élixir de vie. Les seniors aiment randonner. L'époque de La vieille dame indigne, le film de René Allio, où une veuve de 72 ans défiait toutes les conventions parce qu'elle choisissait de mener une vie indépendante, d'aller au cinéma et de conduire une voiture, est révolue. L'étude définit quatre types de seniors en fonction de leur mode de vie. Il y a le vieuxjeune rebelle et dynamique, le gardien conservateur, le technicien qui mise sur toutes les aides, et le flexible, pour qui le sens de la vie réside dans le fait de changer les règles. Les uns veulent préserver l'héritage et tout au plus se promener sur le Rigi, d'autres collectionnent les miles aériens et les croisières, tandis que les troisièmes jouent à fond la carte de l'électronique. Quatre caricatures de seniors sur la base de questionnaires - des profils d'acheteurs intéressants pour notre industrie des biens de consommation. Une petite mention des coûts est inévitable. Sept années supplémentaires sans handicap grâce à la prévention divisent par deux les coûts de santé des troubles chroniques de vieillesse. En forme jusqu'à la fin, telle est la devise. Le statut social et l'éducation ne pèsent apparemment pas dans la balance, en tout cas en Suisse. Un coup d'œil montre qu'ici, ce lundi matin, l'assemblée ne compte pas de bénéficiaires de l'aide sociale. La séance de questions se transforme en consultation: faut-il manger du saumon ou du maquereau? Peut-on en abuser? Il suffit de vouloir, comme le prouvent les actuels records des marathoniens. L'élite des coureurs âgés réunit surtout des papys, dont certains de plus de 80 ans. Les femmes semblent moins attirées par ce genre de records, peut-être parce qu'elles vivent toujours quelques années de plus en moyenne et préfèrent étudier à l'université populaire.

\section{En forme jusqu'à la fin, telle est la devise.}

Du fait de la situation démographique, la recherche sur la vieillesse a le vent en poupe. Le phénomène unique dans l'histoire de pyramides des âges de plus en plus difformes pose d'énormes défis biologiques, médicaux et sociaux. On est aussi vieux que l'image que l'on a de soi. Selon l'étude, les hommes s'estiment un peu plus jeunes que les femmes. Une image de soi souvent confirmée au quotidien, quand des seniors jouent les Superman au guidon d'un VTT. Les femmes sont plus réalistes. Après la conférence, un petit groupe de dames à la tenue discrète et élégante discute devant la pharmacie du coin. Quelques-unes glissent un flacon de vitamine $\mathrm{D}$ dans leur sac à main.

Le malheureux Tithon a payé un lourd tribut. Une fois vieux, il a simplement été enfermé à l'écart. Notre situation est quand même un peu plus gaie. Les perspectives ne deviennent moins roses qu'à partir du quatrième âge (80 et plus). Dès les années 80 , le gérontologue américain Walford prouvait que le jeûne allongeait de $30 \%$ la vie de ses souris de laboratoire. Mais chez les singes déjà, les données sont contradictoires. Avec ou sans jeûne, le terminus finit par arriver. Paul B. Baltes (1939-2006), éminent spécialiste international de la recherche sur l'âge, parlait au sujet de l'avenir du vieillissement «d'espoir avec un ruban de deuil». Et c'est d'ailleurs bien ainsi. 